\title{
TOPOBO: Aspectos motivacionais do uso da robótica com crianças
}

\author{
Mateus Madail Santin, João Alberto da Silva, Silvia Silva da Costa Botelho \\ Programa de Pós-graduação em Educação em Ciências: Química da Vida e Saúde - \\ Universidade Federal do Rio Grande - FURG \\ Avenida Itália Km 8 - Campus Carreiros CEP: 96201-900 Rio Grande - RS - Brasil \\ \{mateus.santin, joaosilva, silviacb\}@furg.br
}

\begin{abstract}
The work used a kit Topobo 100 pieces, toy developed at the MIT media lab. It was proposed the development of robots that carry out certain tasks, such as 'say no' in one of the activities, referring to typical problems of scheduling algorithms that use logical operators such as AND, OR and NOT. The activities were held in a public school in the city of Rio Grande - RS, with children aged between 9 and 10 years who had never had contact with the toy. The experiments were filmed and subsequently evaluated by the group in several respects. The motivational aspect that Kit awakened in children, largely because of the novelty and technological issue that has educational artifact, is discussed in this article.
\end{abstract}

Keywords: Topobo. Educational robotics. Science education.

Resumo. O trabalho realizado utilizou um Kit Topobo de 100 peças, brinquedo desenvolvido no laboratório de mídias do MIT. Foi proposto o desenvolvimentos de robôs que realizassem determinadas tarefas, como por exemplo 'dizer não' em umas das atividades, remetendo a típicos problemas de algoritmos de programação que utilizam operadores lógicos tais como: AND, OR e NOT. As atividades foram realizadas em uma escola pública na cidade de Rio Grande - RS, com crianças de idades entre 9 e 10 anos que nunca tinham tido contato com o brinquedo. Os experimentos foram filmados e posteriormente avaliados em diversos aspectos pelo grupo. $\mathrm{O}$ aspecto motivacional que o Kit despertou nas crianças, muito em função da novidade e da questão tecnológica que este artefato educacional possui, é abordado neste artigo.

Palavras-chave: Topobo. Robótica Educacional. Ensino de ciências.

\section{Introdução}

Este trabalho traz os primeiros resultados de experimentação robótica realizado com um Kit Topobo de 100 peças. As atividades foram realizadas em uma escola pública na cidade de Rio Grande - RS, em uma turma de crianças com idades entre 9 e 10 anos. Estas crianças já participavam de atividades extracurriculares junto ao grupo de pesquisa da universidade, o qual tem o foco na educação básica.

Os experimentos foram filmados e avaliados em diversos aspectos pelo grupo. $\mathrm{O}$ artigo aborda o aspecto do brincar pedagógico e em seguida traz em detalhes os diversos tipos de comercialização do Kit robótico utilizado. Uma seção mostra a dinâmica 
utilizada em sala de aula, bem como as diversas metodologias testadas, e analisa aspectos em cada uma. Por fim, traz uma análise do trabalho focado no aspecto motivacional observado durante os experimentos, com o foco na metodologia que melhor permitiu aos alunos realizarem as tarefas.

\section{O brincar pedagógico}

A brincadeira no contexto escolar é uma possibilidade de atuação pedagógica que auxilia os professores a promover o desenvolvimento e a aprendizagem das crianças (Vygotsky, 1991; Bomtempo, 1997; Bichara, 2001; Baptista da Silva, 2003). No mesmo sentido, Dohme (2002) descreve o brincar na escola como uma técnica em que são postos em prática os conceitos do construtivismo e da aprendizagem por meio da participação ativa do aluno de forma divertida e prazerosa. De acordo com Queiroz, Maciel e Branco (2006), a brincadeira também favorece o desenvolvimento da autonomia, da criatividade e da responsabilidade das crianças quanto as suas próprias ações.

Assim, nota-se que a articulação do potencial da tecnologia e da brincadeira, com as funções da escola, pode contribuir com a transformação dos processos educacionais. Nessa perspectiva, não encontra respaldo a aprendizagem passiva, caracterizada apenas pela absorção de informações, ou a ênfase nas tecnologias em detrimento dos aspectos pedagógicos, políticos, sociais e culturais constitutivos do ambiente escolar.

É permitida à criança em um ambiente não coercitivo, coordenar suas ações para estruturar seus conhecimentos a partir de suas próprias concepções; formular hipóteses e testá-las; usar a iniciativa buscando solucionar problemas que fazem parte do seu interesse; organizar mentalmente suas ideias e expressá-las livremente e com convicção; interagir entre iguais coordenando outros pontos de vista aos seus, construindo regras de participação nas suas atividades, ajuizando em diversas situações o que é melhor para todos. Com isso, abrem-se oportunidades para superar seu egocentrismo, construindo relações que contribuem para o desenvolvimento do raciocínio coerente, e construindo valores sociais que a capacitam a interagir socialmente segundo a moral da cooperação decorrente do respeito mútuo (Brascher, 2000, p. 86). 
A robótica é definida como a ciência dos sistemas que interagem com o mundo real, com ou sem intervenção humana (Ullrich, 1987). É uma área essencialmente interdisciplinar e constitui-se na interlocução entre disciplinas tais como: matemática, engenharia, computação, educação, psicologia, medicina, encontrando-se presente nos diferentes âmbitos da vida cotidiana, nos eletrodomésticos, nas montadoras de automóveis, nas intervenções médicas. No mundo contemporâneo, o robô está entrelaçado no cotidiano, e vem influenciando o nosso modo de viver e interagir, não somente com equipamentos mas também com os seres humanos. Segundo Ullrich (1987), um robô é um equipamento multifuncional e reprogramável, projetado para movimentar peças, materiais e outros tantos dispositivos especializados para o desenvolvimento de inúmeras ações que promovem bem-estar, conforto, saúde e educação. Além disso, nota-se que a temática da robótica mobiliza nas crianças uma satisfação e curiosidade em dominar e interagir com os atuadores robóticos. Nesse sentido, a tecnologia pode ser um instrumento que potencialize o desenvolvimento de diversas habilidades e competências das crianças em função do seu caráter motivacional.

\section{O Kit Topobo}

Nesta seção é apresentado o kit Topobo, e uma breve descrição dos kits disponíveis para comercialização. ${ }^{1}$ Atualmente existem disponíveis para aquisição seis tipos de Kits.

\begin{tabular}{|c|c|}
\hline Starter Set & $\begin{array}{l}\text { Permite construir dezenas de criações diferentes. } \\
\text { - } 92 \text { Passives, em } 9 \text { diferentes formas } \\
\text { - } 95 \text { de força extra-pinos conector } \\
\text { - } 1 \text { Independente (azul) Active } \\
\text { - Bateria } 1 \text { com baterias } \\
\text { - Livreto invenção }\end{array}$ \\
\hline Starter Set + Queen & $\begin{array}{l}\text { Neste kit foi adicionando uma rainha ativa para o conjunto inicial com } 50 \\
\text { unidades. } \\
\text { - } 1 \text { ativa e independente } \\
\text { - } 1 \text { Queen Ativa } \\
\text { - } 92 \text { Passives, em } 9 \text { diferentes formas } \\
\text { - } 95 \text { pinos do conector } \\
\text { - Caixa de bateria } \\
\text { - Livreto invenção }\end{array}$ \\
\hline 100 Piece Set + Queen & $\begin{array}{l}\text { Com este kit pode-se obter uma experiência. } \\
\text { - } 2 \text { Actives Independentes } \\
\text { - } 1 \text { Queen Ativa } \\
\text { - } 85 \text { Passives, em } 9 \text { diferentes formas } \\
\text { - } 95 \text { pinos do conector }\end{array}$ \\
\hline
\end{tabular}

${ }^{1}$ Desenvolvido no laboratório de mídias do MIT por Hayes Raffle e Amanda Parkes, o Topobo é comercializado através do site: http://www.topobo.com 


\begin{tabular}{|c|c|}
\hline & $\begin{array}{l}\text { - } 2 \text { cabos de ligação } \\
\text { - Fonte de alimentação } \\
\text { - Livreto invenção }\end{array}$ \\
\hline $\begin{array}{l}\text { Topobo } 100 \text { Piece } \\
\text { Experimenter Set }\end{array}$ & $\begin{array}{l}\text { Permite Construir centenas de criações diferentes. } \\
\text { - } 85 \text { Passives, em } 9 \text { diferentes formas } \\
\text { - } 95 \text { de força extra-pinos conector } \\
\text { - } 2 \text { independentes (azul) Actives } \\
\text { - Cabo conector } 1 \\
\text { - Caixa de bateria } 1 \text { com baterias } \\
\text { - Livreto invenção }\end{array}$ \\
\hline $\begin{array}{c}500 \text { Piece Workshop } \\
\text { Set }\end{array}$ & $\begin{array}{l}\text { Testado com até } 12 \text { estudantes simultâneos, inclui: } \\
\text { - } 425 \text { Passives, em } 9 \text { diferentes formas } \\
\text { - } 450 \text { de força extra-pinos conector } \\
\text { - } 8 \text { Independentes (azul) Actives } \\
\text { - } 4 \text { Rainha (laranja) Actives } \\
\text { - } 8 \text { cabos de ligação, comprimentos diferentes } \\
\text { - } 4 \text { fontes de alimentação } \\
\text { - } 4 \text { livretos de invenção }\end{array}$ \\
\hline $\begin{array}{c}\text { 1,000 Piece Classroom } \\
\text { Set }\end{array}$ & $\begin{array}{l}\text { Criações absolutamente enormes. Permite até } 24 \text { pessoas. } \\
\text { - } 850 \text { Passives, em } 9 \text { diferentes formas } \\
\text { - } 950 \text { de força extra-pinos conector } \\
\text { - } 16 \text { independentes (azul) Actives } \\
\text { - } 8 \text { Rainha (laranja) Actives } \\
\text { - } 16 \text { cabos de ligação, comprimentos diferentes } \\
\text { - } 8 \text { fontes de alimentação } \\
\text { - } 8 \text { livretos invenção }\end{array}$ \\
\hline
\end{tabular}

Quadro 1- Componentes do kit TOPOBO

Os kits diferem na quantidade de peças ativas e passivas ou por possuírem um ativo diferenciado, denominado rainha. Esta pode agir como uma peça de atividade normal, como também ensinar outros ativos para imitar seu movimento.

O nome Topobo é derivado das palavras topology, botanical, e robot ,constituindo um sistema de modelagem em 3D que permite ser configurado de diferentes formas e programado para se mover fisicamente.

A capacidade de representação 3D do Topobo permite que o aluno contextualize e crie objetos relacionados com a sua percepção. Na figura 1 são ilustradas as peças passivas e a peça ativa. 


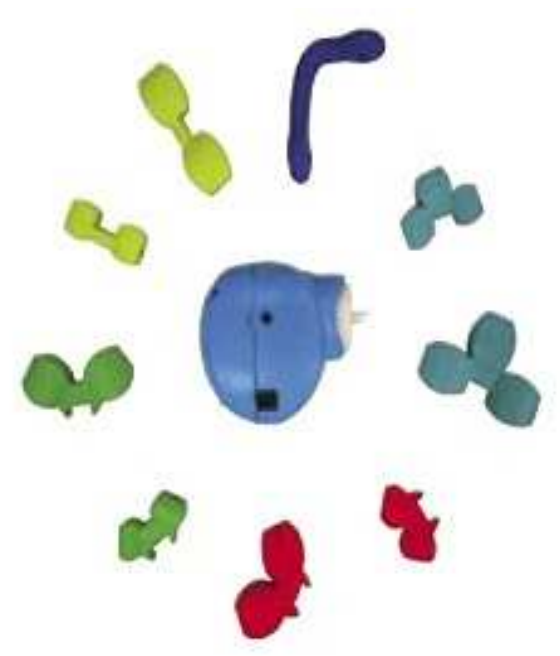

Figura 1 - Conjunto de peças ativas e passivas que formam o Topobo.

O Topobo é composto de dez blocos primitivos básicos que se conectam em diversas orientações. Nove destes blocos são chamados de peças "passivas", pois formam ligações estáticas, sendo que quatro formas geométricas ocorrem em duas escalas. A décima primitiva, denominada "ativa", é um circuito eletrônico envolvido por uma capa plástica composta de um motor associado a componentes eletrônicos, constituindo uma tecnologia embarcada. Quando estas peças são unidas, cria-se uma rede peer-to-peer ${ }^{2}$ descentralizada.

Além dos componentes passivos com função meramente estrutural, o Topobo apresenta o conceito de memória cinética associada aos componentes ativos, a qual, por meio de um botão liga/desliga, permite que a manipulação de tais juntas possa ser registrada. O movimento de cada peça é feito a partir de uma replicação do primeiro movimento, que é feito pelo sujeito que manipula o material. $\mathrm{O}$ usuário pode executar manualmente a movimentação de uma junta através da ação direta das mãos sobre as peças que, por estarem unidas, modificam o movimento da estrutura. Toda ação é salva na peça ativa que armazena o movimento realizado.

Outra tecnologia disponível para a manipulação dos elementos é um tipo especial de dispositivo denominado rainha. Este permite que o sistema replique à outras juntas de peças ativas, o movimento realizado, transmitindo a estas o mesmo movimento executado na rainha.

\footnotetext{
${ }^{2}$ Uma arquitetura de sistemas distribuídos caracterizada pela descentralização das funções na rede, onde cada nodo realiza tanto funções de servidor quanto de cliente.
} 
Na figura 2 é mostrada a forma de programação de uma peça ativa que possui uma estrutura simples passiva, conectada na saída do motor.

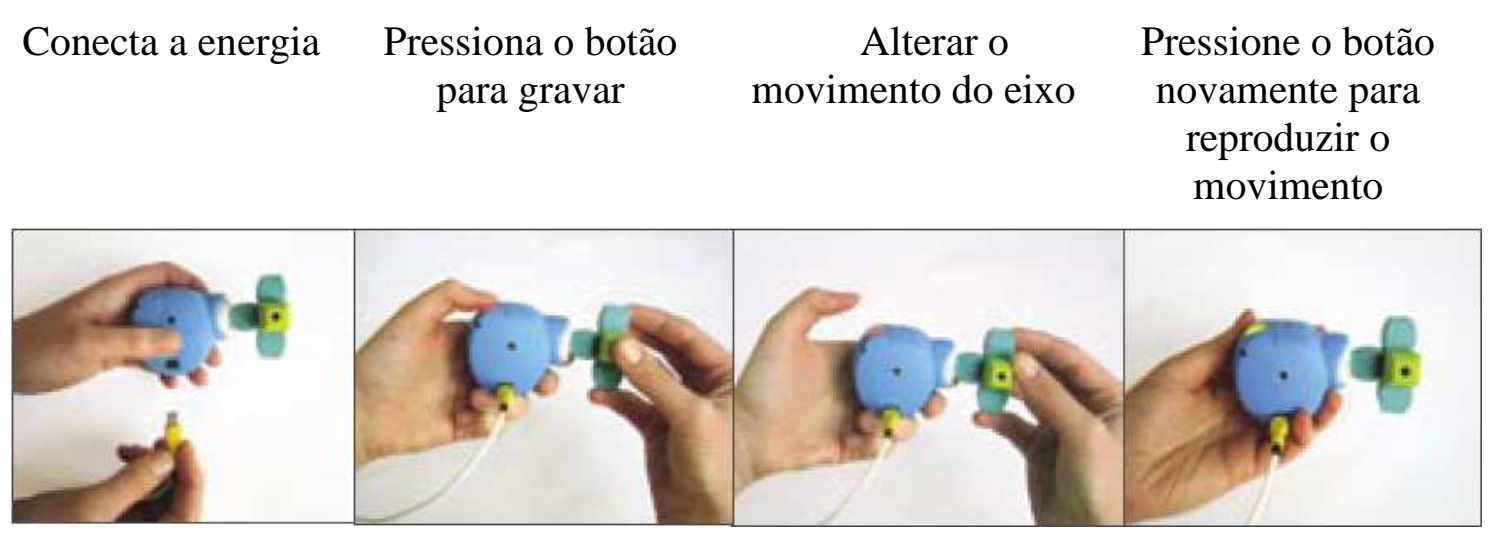

Figura 2 - Programação tátil do Topobo

Um Topobo ativo é programado por manipulação direta, onde cada ativo sincroniza os registros por ele mesmo. Para registrar um movimento um usuário pressiona o botão em um ativo, torce as peças ativas e produz um movimento na criação. Assim, realiza-se uma programação na forma de uma sequência de comportamentos. Ao pressionar o botão novamente, a criação imediatamente entra no modo de reprodução. Neste modo, é reproduzido o movimento várias vezes até que o botão é pressionado pela terceira vez para fazer com que o programa termine.

\section{Análise e Discussão}

A turma foi dividida em cinco grupos, da seguinte forma: um dos grupos composto por cinco crianças e quatro grupos compostos por quatro crianças. Os grupos foram previamente definidos pelo NUEPEC (Núcleo de Estudos em Epistemologia e Educação em Ciências) que realiza outras atividades supervisionadas com as mesmas.

Para a atividade, foram propostas diferentes dinâmicas com os grupos através de um kit robótico de 100 peças do Topobo. Neste artigo é discutido o aspecto motivacional das crianças com o kit, detalhando o trabalho com uma das metodologias propostas. O trabalho foi registrado em vídeo e após analisado criteriosamente os procedimentos executados pelas crianças. 
A metodologia aplicada baseia-se em cinco etapas:

1. Dividir o grupo em duas duplas;

2. Espalhar as peças do kit sobre a mesa, juntamente com dois robôs previamente montados;

3. Demostrar a função dos robôs e a forma de programação através do mecanismo de memória cinética;

4. Reunir as peças com as demais que estavam sobre a mesa;

5. Solicitar a montagem do primeiro robô demostrado, tendo como suporte uma foto do mesmo.

Posteriormente, descreveu-se com detalhes a metodologia aplicada com o primeiro grupo, e, embora algumas alterações na metodologia tenham sido feitas com os outros grupos, o aspecto motivacional foi bastante semelhante. Uma análise detalhada em um dos grupos, demonstrou que o Kit robótico em questão é uma peça que agrega concentração e motivação para as crianças.

Para o grupo em análise, foi mostrado um robô previamente montado e algumas peças espalhadas sobre a mesa, com a intenção que as crianças associassem que o robô apresentado tinha "surgido" das peças sobre a mesa.

O robô foi construído utilizando uma peça ativa, a fim de minimizar a complexidade da montagem. Após, foi contada uma estória para as crianças, em que o robô somente sabia dizer "não". Observou-se que a atenção ao que era explicado era constante. Notou-se no vídeo, que neste momento do experimento, as crianças interagiam pouco, estando voltadas ao objeto e dedicando-se integralmente a desvendar o funcionamento à medida que apresentávamos o robô.

Em seguida, outra construção foi mostrada, e questionou-se o que elas achavam que aquele robô fazia. Eles responderam que o robô dizia "sim". Embora as respostas não estivessem corretas, foi claramente observado que existe uma dedicação em cima da ferramenta e uma associação com a função do robô anterior.

Após demostrada a funcionalidade do robô, que imitava passos de dança, foi observado que as crianças ficaram intrigadas e curiosas pois o movimento fugia ao que elas previamente esperavam. Que era o robô dizer sim, fazer um movimento com a cabeça, a dança envolvia um maior movimento da criação, e isso os despertou ainda mais.

Foram desmontados os dois robôs e as peças misturadas às demais na mesa. A partir deste momento duplas de crianças iniciaram a montagem de um robô que V. $10 \mathrm{~N}^{\circ}$ 3, dezembro, 2012 
repetisse a função de dizer "não". Após algum tempo de observação optou-se por entregar uma foto (modelo) do robô montado para que elas seguissem, pois se observava que somente com as peças em mãos elas não iriam avançar, mas continuavam tentando, pegando as peças de forma aleatória, observando os encaixes.

As crianças se mantinham concentradas nas peças e no modelo (foto do robô), o tempo todo. Observou-se a partir de então que a interação entre elas aumentou, pois precisavam recorrer umas às outras para que as peças fossem alcançadas. Notou-se também que elas não discutiam funcionalidades ou conexões, mas observavam o que a outra dupla fazia. Então uma dupla exclamou:, “Acabou!”, uma clara satisfação em ter realizado a tarefa e uma ansiedade por testar a funcionalidade, ou seja, comprovar se a criação montada diria "não".

Elas esperaram ansiosas para conectar o cabo de energia e programas através do mecanismo de memória cinética à criação. Esta atividade aconteceu automaticamente, bastou alcançar o cabo e eles fizeram a conexão e realizaram todos os procedimentos para que o robô programado fizesse o movimento de "não" com a cabeça. Todavia, alguns estímulos externos, mesmo dentro dessa faixa de captação não foram percebidos em função das experiências anteriores, do grau de atenção e motivação do sujeito que é exposto ao fenômeno (SILVA, 2012).

A intimidade com as conexões elétricas/eletrônicas é notória e inata nas crianças analisadas. Conhecer implica atividade do sujeito, o que implica uma perspectiva de interação entre as sensações do mundo exterior e as capacidades de perceber do cérebro (SILVA,2012). Enquanto isso, a outra dupla seguia montando o robô, eles focavam no modelo da foto e no modelo criado pela dupla que executou primeiro a tarefa, com as peças em mãos moviam-se mais rapidamente para montar, o foco e a concentração nas peças e no modelo ficaram maiores.

A dupla que montou primeiro interagiu pela voz, e pediu para que o robô dissesse "não". Assim, risadas aconteceram e um ar de satisfação tomou conta da dupla em função da resposta positiva do robô ao comando. Enquanto a dupla não havia concluído a criação, optamos por solicitar modificações na programação, como por exemplo, pedimos para que o robô dissesse "não" mais rápido, prontamente manipularam a criação para que esta tarefa fosse executada.

Após o termino da criação pela segunda dupla, eles fizeram os mesmos testes de programação, que era dizer "não e dizer "não" mais rapidamente. Nota-se que a 
satisfação não era a mesma, pois eles terminaram após a outra dupla, mas se mantiveram interessados.

Então mostramos o modelo através de uma foto do robô que "dança" e solicitamos que eles o montassem. Notou-se nesta etapa um entendimento maior por parte das duplas. Ambas iniciam a montagem pela peça ativa. Observou-se que houve uma apropriação da função da rotação do motor, e que era aquela peça que permitia à criação executar as tarefas, dizer "não" e "dançar".

As crianças levantaram-se da cadeira para melhor acomodarem-se e agirem com as peças sobre a mesa. Em função do trabalho estar sendo realizado em grupo, e que somente uma peça ativa foi necessária para executar a construção, ocorre que, quando uma das crianças da dupla tomou em mãos a peça ativa, a outra ficou observando o modelo da foto e o que a criança que tem a peça ativa está montando, ela toma a função de sugerir peças. A outra criança espontaneamente inicia a montagem da cabeça, a qual tem a conexão somente com peças passivas. Ao mesmo tempo em que estão conferindo o modelo também estão interagindo com mais frequência. Nessa situação, a dupla que na primeira montagem terminou tardiamente em relação ao primeiro grupo, agora termina primeiro. Observamos que existiu uma maior reflexão entre eles antes de colocar as peças. Eles tinham confiança no que estavam montando e se o que foi montado refletia o modelo.

Solicitamos que eles fizessem o robô dançar outra música, e eles associaram a alteração da programação, em função da velocidade e do tempo, e reprogramaram a peça ativa, fazendo com que ele "dançasse" mais rápido.

Quando a dupla que se encontrava tardia na montagem, concluiu, exclamaram “terminamos!”. A aprendizagem torna-se então um processo de cuidado para que esse amadurecimento aconteça (SILVA, 2012). Mais que depressa uma das crianças se levanta e vai em direção do robô que estava funcionando para retirar o cabo de energia e testar a criação deles. As crianças ficam paradas e concentradas para ver a criação entrar em funcionamento. O tempo total da atividade foi de aproximadamente vinte minutos. 


\section{Considerações}

Os artefatos tecnológicos produzem sentimentos de curiosidade e de motivação muito grandes nas pessoas. Pode-se notar que crianças ficam muito interessadas nesse tipo de material, evidenciando forte interesse na manipulação e na resolução de problemas. Comprovou-se que o uso da tecnologia desencadeia processos mais profundos de concentração, pois o sujeito mantém foco no cumprimento da tarefa. Além disso, mesmo a atividade possuindo relativo grau de dificuldade, o sujeito se sente desafiado e empolgado na busca da solução, mostrando-se compenetrado e focado.

Observa-se que durante os experimentos consideramos positivamente o fato que durante as explicações de funcionamento, os alunos permanecem em silêncio e observando cuidadosamente as explicações, mostrando um nível de concentração. Durante a montagem embora um dos membros do grupo tomava a frente, o outro membro da dupla explorava as peças, e contribuía para executar a tarefa. Durante a finalização da construção, ambos se interessam por explorar o robô e fazendo testes através da programação do equipamento.

\section{Referências}

Baptista da Silva, C. C. (2003). O lugar do brinquedo e do jogo nas escolas especiais de educação infantil. Tese de doutorado. Curso de Pós-Graduação em Psicologia. Instituto de Psicologia. Universidade de São Paulo. São Paulo, SP.

Bichara, I. K. (2001). Brincadeiras de meninos e meninas: segregação e estereotipia em episódios de faz-de-conta. Temas em Psicologia da SBP, 9 (1), 19-28.

Bomtempo, E. (1996) A brincadeira de faz-de-conta: lugar do simbolismo, da representação, do imaginário. Em T. M. Kishimoto (Org.). Jogo, brinquedo, brincadeira e a educação. São Paulo: Cortez.

Brascher, A C. (2000). Objetivos socioemocionais das atividades de conhecimento físico. Ciência \& Educação, 6 (2), p. 75-87.

Dohme, V. A. (2002). Atividades lúdicas na educação: O caminho de tijolos amarelos do aprendizado. Dissertação de Mestrado. São Paulo: Universidade Presbiteriana Mackenzie.

Queiroz, N. L. N; Maciel, D. A. \& Branco, A. U. (2006). Brincadeira e desenvolvimento infantil: um olhar sociocultural construtivista. Paidéia, 16 (34), 169-179

Silva, J. A. (2012). Sensação e Percepção no Contexto dos Estudos sobre Aprendizagem. (dados não publicados) 
Ullrich, R. (1987). A Robótica: uma introdução. Rio de Janeiro, RJ: Campus.

Vygotsky, L. S. (1991). A formação social da mente: o desenvolvimento dos processos psicológicos superiores. São Paulo: Martins Fontes, $4^{\mathrm{a}} \mathrm{ed}$. 